STUDENT DROPOUT AS A MULTI-STAGED PROCESS

Is Student Dropout at University a Multi-Staged Process? A Phase-Orientated View on

Quitting Studies and Changing Majors

Lisa Bäulke

University of Augsburg, Germany

Carola Grunschel

University of Münster, Germany

Markus Dresel

University of Augsburg, Germany

Manuscript Submitted for Publication

THIS PAPER IS UNDER REVIEW.

Please do not cite or distribute any portion without authors' permission. 


\section{Is Student Dropout at University a Multi-Staged Process? A Phase-Orientated View on Quitting Studies and Changing Majors}

Student dropout from university is a major issue in higher education in many countriesinternational studies have revealed student dropout rates as high as $25 \%$ to $45 \%$ of first-year students never graduating (Heublein, 2014; Heublein \& Wolter 2011; OECD, 2017; Solberg Nes et al., 2009). According to Mashburn (2000), student dropout can be understood as a process, as a student's final decision to leave university can be predicted by cognitions of withdrawal, including thoughts of quitting, search intentions, and dropout intentions. Hence, student dropout seems to be based on a longer-lasting decision making process. For instance, Heublein et al. (2017) found that German students, who quit their studies, are on average enrolled at university for four semesters.

So far, only a few studies have dealt with student dropout as an ongoing process with different phases. This research has, although insightful, frequently been descriptive, explorative, and qualitative (e.g., Heublein, 2014; Pascarella et al., 1986; Rivière, 1999). It has provided valuable and rich findings on cognitions, motivations, and emotions prior to and after student dropout, but has not considered different phases of the individual dropout process based on a quantitative hypothesis testing approach. This does not allow conclusions to be drawn regarding specific determinants of the phases. However, differentiated insights into this individual process can be helpful for an effective and early detection of students who potentially drop out from their studies and would profit from targeted support in this situation. Additionally, prior research on student dropout did not differentiate clearly between quitting studies and changing a major - although these two decisions may clearly fulfil different functions and may be associated with different consequences for the individual (Cope \& Hannah, 1975; Stratton et al., 2005).

Hence, the aim of the present research is to develop and test a differentiated model of the process of student dropout with a study in the German context that specifies distinct phases 
and additionally distinguishes between quitting completely and changing one's major.

Theoretically, we mainly refer to the decision-making model by Betsch (2005) and to the Rubicon model of action phases (Achtziger \& Gollwitzer, 2010), which indicate that each phase is characterized by specific information processes. Hence, we want to contribute to a better understanding of the student dropout process from first perceptions of a non-fit between student and studying environment up to the actual decision to drop out.

\section{Conceptualizing Student Dropout}

The literature provides a series of conceptualizations of student dropout using various terms (e.g., attrition, retention, persistence), which should not be used synonymously (cf. Berger et al., 2005). In line with the definition of Berger et al. (2005), we refer to student dropout in the case of "a student whose initial goal was to complete at least a bachelor's degree, but did not" (p. 12). More comprehensive definitions reflect that dropout can be characterized by individual and environmental factors. Particularly, Tinto (1975) claimed that "dropout represents the failure of individuals, of given ability and goal commitment, to achieve desired educational goals" (p. 78), whereas Heublein and Wolter (2011) extended this view to a perspective that also considers environmental factors: The authors conceptualized student dropout as a complex event where individual, institutional and social factors that affect studying are superimposed. Accordingly, student dropout can be seen as a multicausal, ongoing process (see also Blüthmann et al., 2008), resulting from a dropout intention (Mashburn, 2000).

A successful completion of studies can have a great positive impact on a person, both for instance with regard to higher income and better health (Solberg Nes et al., 2009). On the contrary, student dropout can be associated with social and individual costs (De Lourdes Machado et al., 2011; Sarcletti \& Müller, 2011). For instance, it represents a big cost factor for society, existing relationships with fellow students can end, and life planning must be 
adjusted. Therefore, analyzing its conditions is becoming a focus of university research (Blüthmann et al., 2008).

Prior research predominantly investigated the relevance of various potential determinants of student dropout, such as family background, individual attributes, and precollege schooling experience (e.g., Arendt, 2013; Braxton et al., 2000; Heublein et al., 2003; Respondek et al., 2017). For example, in the German context, three main distal reasons for student dropout could be identified, including problems of financing studies, performance problems, and lack of study motivation (Heublein 2014). Also, many international studies indicated the significant role that financial hardships plays for student dropout and how financial aid could prevent this (e.g., Chen \& DesJardins, 2008; Melguizo et al., 2010; Scott et al., 2008). Moreover, deficient performance (e.g., Duque, 2014) and insufficient motivation (e.g., De Witte \& Rogge, 2013; Litalien \& Guay, 2015; Morrow \& Ackermann, 2012; Vallerand et al., 1997) also proved to be essential causes of student dropout in international studies and might be the starting point for developing a dropout decision. Similarly, meta-analyses point out that student engagement is positively related to academic achievement (Lei et al., 2018), and certain motivational aspects such as academic goals and academic self-efficacy show besides academic-related skills moderate relationships with retention (Robbins et al., 2004).

Frequently, the term student dropout is used in a very broad sense. However, the term must be refined. Several researchers recommended differentiating between quitting studies completely and changing a major (e.g., Cope \& Hannah, 1975; Stratton et al., 2005; Wolter et al., 2014), as neglecting this differentiation can bias the results concerning student dropout. In the present paper, we consider both phenomena separately to avoid this bias, although the main focus is to examine the process of student dropout in terms of quitting studies completely.

\section{Prior Research on the Process of Student Dropout}


As of yet, the few existing studies on the process of student dropout mostly implicitly assume different phases and allocate certain causes to different phases of student dropout. For instance, Tinto’s Student Integration Model (1975) postulates that student dropout is determined by the degree of social and academic integration of a student within the academic system. Triggered by failed integration, the process of student dropout presumably already starts at the beginning of studying. Rivière (1999) also postulated this mechanism in his qualitative research. Here, student dropout was conceptualized based on three periods: predropout, dropout, and post-dropout. In the pre-dropout phase, students experienced a maladaptation between themselves and the institution, resulting in decreased commitment to their studies, which can lead to actual dropout. The post-dropout phase is, according to Rivière, characterized by a moratorium in which self-reactualization can take place. Mashburn's (2000) model of the psychological process of university student dropout adapted from an employee turnover model by Hom et al. (1992) implicitly models a process of student dropout as withdrawal cognitions proved to predict actual dropout. According to Mashburn, these withdrawal cognitions present a higher single-factor of three aspects closely related in the student dropout process, namely thoughts of quitting, search intentions about alternatives to the actual degree program and dropout intentions.

Taken together, prior studies give first evidence that developing a decision of student dropout is based on and can be conceptualized as a multi-staged process. However, researchers have not explicitly developed a differentiated process model. We therefore present in the following a detailed approach for understanding the process of student dropout that is based on the theoretical perspectives of decision-making and action-phase models.

\section{Towards a Differentiated Process Model of Student Dropout}

Applying cognitive models of decision-making processes and an action-phase model can help to identify relevant phases of student dropout as the development of dropout intentions seems to be based on motivated long-term processes characterized by certain cognitive and 
behavioral patterns (such as the perception of a poor fit between student and institution, ruminating, and search for information). For the purpose of identifying phases of the student dropout process, two models seem to be especially helpful (see Figure 1): The decisionmaking model of Betsch (2005) and the Rubicon model of action phases (Achtziger \& Gollwitzer, 2010), since these models illustrate the processes of forming a decision or getting to an action in a differentiated way.

The decision-making model of Betsch (2005) focuses on individual decision-making as a process under control of a person and environment. Here, three decision-making phases are anticipated: a preselection, a selection, and a postselection phase. According to the ideal type model, the preselection phase is characterized by generating options followed by seeking decision-relevant information, and eventually identifying decision-making situations. The selection phase involves assessing possible consequences and thereafter reaching a decision. Postselectively, the action is implemented (and feedback learning takes place). To gain a better understanding of the process of dropout intentions, considering the preselection phase and the selection phase of this model seem to be beneficial, as here, the process until the actual decision is well differentiated.

A different yiew that might illuminate the process of student dropout results from applying the general Rubicon model of action phases. A benefit of this model is the description of certain mindsets of each phase (see Ghassemi et al., 2017). It proposes a predecisional, a preactional, an actional and a postactional phase (Achtziger \& Gollwitzer, 2010). The predecisional phase is characterized by the contemplation of feasibility of certain wishes, and the desirability of potential outcomes with open-mindedness, ending in transforming the wish into a specific goal. Then, in the preactional phase, individuals consider how to best pursue the goal with cognitive tuning towards the information. This leads to enacting these plans in the actional phase where the focus of attention is on sustaining the course of action. Finally, an evaluation of the action outcome with an objective mindset takes 
place in the postactional phase. For the conception of our process model on dropout intentions, characteristics of the predecisional, preactional and actional phases are especially interesting, since here the process until the action is well differentiated.

To understand the ongoing process of developing dropout intentions until the actual student dropout, we integrate the model of Betsch and the Rubicon model into one model so that the process of student dropout can be differentiated sufficiently (Figure 1). We assume that each phase includes specific information processes. As students have different alternatives after the decision to drop out from studies, we aim to differentiate in our model between intentions to quit studies completely and intentions to change a major. For both versions, we assume that the same order of processes takes place until the final decision.

It can be assumed that the process of developing a dropout intention (or an intention to change one's major, respectively) starts with a perception of a non-fit between studying in general (or the specific study content and context) and the individual (non-fit perception). This first sensing of incongruence between the student and studying may constitute the first phase of a dropout process, in which a wish for a change of the current situation develops. As a consequence, resistance as a decreased commitment to studying and unfavourable emotional experience could take place (Gollwitzer, 2012). This corresponds to the preselectional phase of Betsch's (2005) model as a decision-problem is now identified. For the individual, this may create a burden, thereby leading to unsystematic thoughts of quitting studies completely or changing a major, respectively. In this rather heuristic information processing, these thoughts might be unsystematic and widely spread (thoughts of quitting studies completely / of changing a major). They might revolve around the feasibility of certain wishes and the desirability of potential action outcomes until this phase ends with a commitment to the goal to sort out the issue of quitting studies completely or changing one's major, respectively (see Achtziger \& Gollwitzer, 2010; Gollwitzer, 2012). According to the model of Betsch (2005), different options can now be generated and a deliberation between these starts. As a 
consequence, this might initiate the next phase of the dropout process in terms of deliberating values and expectations - the student consciously weighs up between remaining in the course of studies compared to alternatives (deliberation). Here, due to a focus on internal aspects, the assimilation of new information might be limited, focusing more on the specific goal. The Rubicon model postulates here a fiat tendency, meaning that the goal of quitting studies obtains liabilities. In line with the model of Betsch (2005), a targeted information search might happen after the generation of options, so we theoretically assume that informing through a targeted search for information about non-university activities (or other majors) could happen next (information search). In the Rubicon model of action phases, this step corresponds to the preactional phase as the planning of a concrete action (information search) has started and the student pursues a concrete goal (e.g., to find out more about alternatives). Finally, the process might end with a decision to quit studies completely (or to change a major). Relief and feasibility orientation can take place before the final decision is implemented (decision made). This step corresponds to the selectional phase of Betsch's model (2005) as a decision is being made, as well as to the actional phase of the Rubicon model of action phases as the student starts to establish the action of quitting studies completely or changing major in a goal-oriented way.

\section{Correlates Associated with Student Dropout}

In order to test the assumptions of a process model of student dropout, it is important to consider a selection of possible correlates more closely in relation to the model. Here, focusing on individual determinants is particularly interesting, since these have an influence on the course of studies (Gensch \& Kliegel, 2012). Additionally, due to social changes, today problematic study conditions are rarely mentioned, but individual determinants such as test anxiety or a lack of motivation have increased (Blüthmann et al., 2008; Respondek et al., 2017). Hence, it is of great interest to take a closer look at these correlates of student dropout when analyzing its process - as it can be assumed that different phases of developing a 
dropout intention relate to a different degree to them. Taking previously described models of student dropout into account (e.g., Bean \& Metzner, 1985; Tinto, 1975), we consider a selection of possible correlates of student dropout more closely in relation to the model. They can be clustered into emotional (subjective well-being, anxiety), motivational (academic selfconcept, subjective task value), behavioral (academic procrastination) and cognitive/affective variables (learned helplessness).

From an emotional perspective, high subjective well-being can be seen as a protective factor against student dropout as it relates to important study-relevant factors (such as academic procrastination and performance; Grunschel et al., 2016; Ruthig et al., 2007; Witter et al., 1984). Furthermore, academic emotions—especially anxiety—are closely related to academic achievement (e.g., Pekrun et al., 2009; Pekrun et al., 2002) and achievement anxiety is positively related to dropout intentions (e.g., Respondek et al., 2017).

Concerning motivational variables, academic self-concept (the composite view of oneself in an academic context, Bong \& Skaalvik, 2003) as well as subjective task value affect student dropout (e.g., Chemers et al., 2001; DeWitz et al., 2009). Additionally, if the expectation to successfully complete the studies and the value of studying decreases in the course of the semester, dropout intentions are increased (Dresel \& Grassinger, 2013). In this way, these components of study motivation can be seen as robust and consistent predictors of academic success (Heublein et al., 2017; Robbins et al., 2004; Zajacovy et al., 2005).

Taking a behavioural variable into account, academic procrastination (a voluntary delay of an intended action despite knowing about its negative consequences; Grunschel et al., 2016; Klingsieck, 2013; Simpson \& Pychyl, 2009; Steel, 2007) was found to be positively linked to dropout intentions (Bäulke et al., 2018).

Finally, concerning a cognitive/affective variable, learned helplessness (the belief that a person has no control over what happens to them due to prior repetitive failure in a performance; Maier \& Seligman, 1976) was taken into account in the present study. Krejtz 
and Nezlek (2016) found that it has a domain specific component, showing that learned helplessness in a certain subject leads to lower performance in this subject. It can therefore be assumed that learned helplessness is positively linked to student dropout.

\section{The Current Research}

Until now, there has been little knowledge on the motivational process of developing dropout intentions. In order to understand the evolving process until the actual student dropout, this study aims to constitute the development of dropout intentions as an ongoing process under the perspectives of decision-making and action-phase models. On that account, we proposed a model, differentiating between intentions to quit studies completely and to change a major. Overall, we investigated three hypotheses.

First, based on the decision-theoretical model of Betsch (2005) and the Rubicon model of action phases (Achtziger \& Gollwitzer, 2010), we hypothesized that our five assumed phases (non-fit perception, thoughts of quitting/changing, deliberation, information search and decision made) exist. Additionally, we claim that these phases of intentions to quit studies completely and intentions to change a major are separate aspects and therefore distinguishable (Hypothesis 1).

Furthermore, we assume that students can be allocated to different phases and go through previous phases before moving on to the next phase of the process. Therefore, we hypothesize that the mean scores of the subscales of intentions to quit studies completely and intentions to change a major follow the order of the phases-implying that there are lower mean scores in advanced phases (Hypothesis 2).

For substantiating the anticipated process model, we finally aim to investigate if the manifestations of the assumed phases correlate with the assortment of theoretically derived emotional, motivational, behavioral and cognitive/affective variables associated with student dropout. As decision-theoretical models indicate, these variables are especially important in early predecisional phases. This is because in early decision-making phases, there is a wide 
receptiveness (as in the deliberating mindset in which a person openly weighs between value and expectancy of a certain goal; see Gollwitzer, 1990; 2012). However, in later stages, the focus of attention is narrowed (in an implemental mindset, a person only focuses on implementing the goal until information processing only happens in favour of the goal; Achtziger \& Gollwitzer, 2010). Therefore, we expected a specific correlational pattern, namely decreasing correlation strength between these variables and dropout intentions with proceeding phases. It is to be assumed that the direction of the correlations of the phases of intentions to quit studies completely and intentions to change a major are substantially positive with anxiety, academic procrastination and learned helplessness, as well as substantially negative with subjective well-being, academic self-concept and subjective task value (Hypothesis 3).

\section{Methods}

\section{Procedure and Participants}

We contacted all students (in total 19,318 students) of a university in southern Germany, that offers a wide range of almost 90 degree programs in humanities and social sciences, economics and law, natural and technical sciences, as well as computer sciences, via e-mail. Students were invited to our online survey regardless of their major and semester.

Participation was voluntarily and after completing the questionnaire, students could receive a voucher worth five Euros.

A total of 1,525 students started the online survey, and 1,206 participants completed the questionnaire (7\% of students contacted). 201 participants were excluded due to unreasonable working time while completing the questionnaire (less than 1.5 seconds per item). As a consequence, $N=1,005(53 \%$ female; $47 \%$ male; mean age $=23.0$ years, $S D=3.5)$ participants were included in the data analyses. The average processing time for completing the questionnaire was 22.0 minutes with a median of 21.0 minutes. The students were enrolled in different degree programs: the majority of participants were enrolled in the fields of 
economics and law (23\%), followed by teaching (21\%), mathematics and natural sciences (19\%), social sciences (17\%), cultural sciences (12\%) and engineering (6\%). They had completed an average of 4.54 semesters $(S D=3.83)$.

\section{Variables and Measures}

To investigate our research questions, we newly developed items for measuring intentions to quit studies completely and intentions to change a major. As correlates associated with student dropout, subjective well-being, anxiety, academic self-concept, subjective task value, academic procrastination and learned helplessness were assessed with established self-report scales. In the online questionnaire, the participants could only continue to the next page when they had completed all the current items.

\section{Phases of Intentions to Quit Studies Completely and Intentions to Change a Major}

To measure the assumed phases of the process of intentions to quit studies completely and intentions to change a major, we newly developed two versions of a multifaceted scale, since no scales existed that strictly distinguish between different phases of the process of student dropout on the one hand, and between intentions to quit studies completely and intentions to change a major on the other hand. Based on the model assumptions presented above, we distinguished between non-fit perceptions, thoughts of quitting/changing, deliberation, information search and decision made. We assessed each phase by using three items (see full wording of sample items in Table 1 and descriptive statistics as well as internal consistencies in Table 2) alongside six-point Likert-scales ranging from 1 (disagree completely) to 6 (agree completely).

\section{Subjective Well-Being}

We assessed subjective well-being by using the German Single-Item Scale L1 (Beierlein et al., 2014). The item reads as: "How satisfied are you at the moment, all in all, with your life?" Responses to the item ranged from 1 (entirely unsatisfied) to 11 (entirely satisfied). 
Measuring anxiety in a learning context, four items ("Thinking about my studies makes me feel uneasy") of the Achievement Emotions Questionnaire (AEQ), developed by Pekrun et al. (2005) were adapted to the academic context. They were presented on a six-point Likert-scale ranging from 1 (disagree completely) to 6 (agree completely).

\section{Academic Self-Concept}

To assess academic self-concept, we used a five-item subscale from the German scales for the assessment of school's self-concept (SESSKO; Schöne et al., 2002), adapted to the academic context. The five-point bipolar response scale of the items consisted of item pairs containing opposite statements (sample item pair: "Learning new things is hard ... easy for me").

\section{Subjective Task Value}

We measured subjective task value with a six-item scale that we had already used in several prior studies (e.g., Authors, 2019). A sample item reads as: "My studies have a personal benefit for me". The items were presented with Likert-type response scales ranging from 1 (disagree completely) to 6 (agree completely).

\section{Academic Procrastination}

Assessing academic procrastination, we used a short version of the German translation of the Tuckman Procrastination Scale (TPS, Stöber, \& Joormann, 2001; Tuckman, 1991) with ten items with high factor loadings (see Tuckman, 1991). A sample item reads as: "I needlessly delay finishing jobs in my studies, even when they're important". The response scale of the items ranged from 1 (not correct at all) to 5 (fully correct).

\section{Learned Helplessness}

To measure learned helplessness in the academic context, we adopted and extended the helplessness scale of Breitkopf (1985), resulting in six items. A sample item reads as: "Even if I make an effort, I have no success in my studies". The item response scale ranged from 1 (disagree completely) to 6 (agree completely). 
Descriptive statistics and internal consistencies of these correlates associated with student dropout are displayed in Table 3.

\section{Analyses}

To examine our first hypothesis concerning the separability of the presumed phases, at first we conducted confirmatory factor analyses and compared model fit indices between different models. In a next step, we compared five-factor models with models consisting of four factors, which were derived from the conflation of two factors each. To test our second hypothesis concerning the order of the presumed phases, we took the latent mean scores of the subscales of each phase into account. Our third hypothesis concerning correlations with variables associated with student dropout was tested with latent correlations of our assumed phases with subjective well-being, anxiety, academic self-concept, subjective task value, academic procrastination and learned helplessness.

Confirmatory factor analyses and latent models were executed using Mplus 7 by Muthén and Muthén (1998-2011), considering chi-square $\left(\chi^{2}\right)$, root-mean-square error of approximation $(\mathrm{RMSEA} \leq 0.08)$, comparative fit index $(\mathrm{CFI} \geq 0.95)$ and tucker lewis index (TLI $\geq 0.95)$ according to the criteria of $\mathrm{Hu}$ and Bentler (1999). The correlates associated with student dropout (anxiety, academic self-concept, subjective task value, academic procrastination and learned helplessness) were latent variables. These variables were parceled according to the item-to-construct balance approach (Little et al., 2002).

\section{Results}

\section{Separability of the Postulated Phases in the Process of Student Dropout}

To test the separability of our postulated phases (Hypothesis 1), we considered model fit indices of various reasonable models. The hypothesized ten-factor model (Figure 2), that combines the five phases of intentions to quit studies completely and intentions to change a major with admitted correlations of corresponding phases, showed an acceptable fit $\left(\chi^{2}=2304.5 ; d f=380 ; p<.001 ;\right.$ RMSEA $\left.=.07 ; \mathrm{CFI}=.94 ; \mathrm{TLI}=.93\right)$. This confirms our 
hypothesis as it emphasizes the separability of the phases. Moreover, small to moderate correlations between these corresponding phases $(.08<r<.28)$ support the idea that these processes require separate consideration. This indicates that phases of intentions to quit studies completely and intentions to change a major are separate aspects and therefore distinguishable. As a consequence, we conducted separate analyses for intentions to quit studies completely and intentions to change a major to further consider the differentiation between these constructs. That is, we estimated two separate five-factor models, one each for intentions to quit studies completely and intentions to change a major. Both models for intentions to quit studies completely $\left(\chi^{2}=422.7 ; d f=80 ; p<.001 ;\right.$ RMSEA $=.07 ; \mathrm{CFI}=.98$; $\mathrm{TLI}=.97)$ and intentions to change a major $\left(\chi^{2}=390.7 ; d f=80 ; p<.001 ;\right.$ RMSEA $=.06$; $\mathrm{CFI}=.98 ; \mathrm{TLI}=.97)$ showed good data fit.

In a next step, we wanted to examine if our assumed phases can be robustly differentiated, and, in that sense, if a separation between them is necessary. Therefore, we compared the five-factor models (in separate analyses for intentions to quit studies completely and intentions to change a major) with four-factor models, resulting in all possible combinations of phases. For instance, we compared the five factor model (consisting of one factor each for [1] non-fit perceptions, [2] thoughts of quitting, [3] information search, [4] deliberation, [5] decision made) with models with two merged phases (consisting of one factor each for [1] non-fit perceptions, [2] thoughts of quitting and information search were merged, [3] deliberation and [4] decision made). The fit of these four-factor models was not as good (RMSEA > .15; CFI < .92; TLI < .90) and significantly worse than five-factor models (all $p<.001$ ). In addition, a two-factor model without differentiating between phases did not fit the data in an acceptable way $\left(\chi^{2}=13512.0 ; d f=404 ; p<.001 ; \operatorname{RMSEA}=.18 ; \mathrm{CFI}=.58\right.$; $\mathrm{TLI}=.55)$ and was significantly worse than the hypothesized ten-factor model $(p<.001)$.

In conclusion, our first hypothesis can be supported as model fit indices indicate that the five postulated phases are factorially separable for both intentions to quit studies completely 
and for intentions to change a major. Based on the results of the confirmatory factor analyses, we constituted two versions with five subscales each with good internal consistencies (see Table 2).

\section{Order of the Postulated Phases}

Testing our second hypothesis regarding whether the assumed phases follow the presumed order, we considered latent mean scores and confidence intervals of the factors separately for all phases of intentions to quit studies completely and intentions to change a major (Table 2). The results showed that the latent mean scores of intentions to quit studies completely as well as of intentions to change a major were lower in advanced phases. Confidence intervals indicate many significant differences that confirm the order of the phases to a great extent, supporting the second hypothesis. Only for intentions to quit studies completely, confidence intervals indicated that the postulated first three phases (non-fit perception through deliberation) have similar mean scores and thus seem to occur at similar periods of time. However, for intentions to change a major there were significant differences in mean scores indicated by non-overlapping confidence intervals. Taken together, our second hypothesis was supported to a larger part, as most mean scores followed the presumed order.

\section{Associations of Postulated Phases in the Process of Student Dropout with Emotional,}

\section{Motivational, Behavioural and Cognitive/Affective Determinants}

Testing our third hypothesis concerning interrelations of intentions to quit studies completely and intentions to change a major with variables that are potentially associated with student dropout (Hypothesis 3), single latent bivariate correlations were estimated (Table 4). We found significant positive correlations of our assumed phases (both for intentions to quit studies completely as well as for intentions to change a major) with anxiety, academic procrastination, and learned helplessness as well as significant negative correlations with subjective well-being, academic self-concept and subjective task value. A decreasing correlation strength with progressing phases could be noticed on a descriptive level. This 
decreasing descriptive strength of the correlations with progressing phases was noticeable at all emotional, motivational, behavioral, as well as cognitive/affective variables. This was especially evident for intentions to quit studies completely, whereas for intentions to change a major the correlation strength increased slightly again — on a descriptive level—when the decision was made.

In conclusion, our third hypothesis is supported, as the phases of quitting studies and changing a major correlated significantly and to a substantial amount with the selected variables associated with student dropout, supporting our assumptions on the postulated model.

\section{Discussion}

Student dropout is a phenomenon that is of increasing importance in higher education research and can cause serious consequences. There are some indications in the previous literature that student dropout can be conceptualized as an ongoing, motivational process (e.g. Mashburn, 2000; Morrow \& Ackermann, 2012; Rivière, 1999; Robbins et al., 2004; Tinto, 1975). Therefore, we assumed that research should focus on examining this process more closely in order gain a better understanding so appropriate interventions can be provided. Hence, we postulated that dropout intentions - as they can be seen as a precursor of actual student dropout (see Mashburn, 2000) — are the result of a long-term process. Based on the decision-making model by Betsch (2005) and the Rubicon model of action phases (Achtziger $\&$ Gollwitzer, 2010), we assumed that this process starts with a perception of non-fit between student and institution (Tinto, 1975), followed by thoughts of quitting/changing (e.g., thoughts of quitting; Mashburn, 2000), deliberation and information search (e.g., search intentions; Mashburn, 2000), and eventually leading to a final dropout decision. The aim of the present study was to examine whether developing dropout intentions can be considered as an ongoing process, while differentiating between intentions to quit studies completely and intentions to change a major. 
Results concerning Hypothesis 1 (addressing the separability of the assumed phases and distinctions between quitting studies completely and changing majors in the process of student dropout) showed that our theoretically assumed phases are separate and that quitting studies and changing majors should be considered separately, as our estimated ten-factor model showed good data fit. Moreover, correlations between the corresponding phases of intentions to quit studies completely and intentions to change a major were rather small. In line with Cope and Hannah (1975) as well as Stratton et al. (2005), these findings emphasize the importance of considering quitting studies completely and changing a major as two different phenomena not only theoretically, but also empirically. Additionally, the comparison of fit-indices between the five-factor models and the four-factor models especially elucidates the robustness of the five-factor models and this finding thereby emphasizes the separation of the assumed phases. Taken together, the development of intentions towards student dropout can be separated into five phases and there should be differentiated between intentions to quit studies completely and intentions to change a major.

A second major result of our research was that the latent mean scores of intentions to quit studies completely and intentions to change a major decreased as the phases progressed. This result confirms our assumed order as it can be presumed that the phases build on each other so that preceding phases cause subsequent ones. For example, students who already have their first thoughts about quitting their studies completely or changing a major still end up with a non-fit perception between themselves and the institution. Furthermore, the latent mean scores of changing a major were predominantly higher than the latent mean scores of quitting studies completely. This indicates that students are more likely to consider changing their major than actually quitting their studies completely. Having a closer look at the differentiation of phases within the student dropout process, the confidence intervals of the latent mean scores implied that non-fit perception, thoughts of quitting and deliberation occur at the same period of time. This might indicate that a student who doubts his/her studies at all, might experience a non-fit 
with the institution and have at the same time thoughts of quitting studies and already weighs between staying and alternative options, or in other words: this student might be caught up in a vicious circle. However, for intentions to change a major we found significant differences in mean values indicated by non-overlapping confidence intervals. This might be seen as a hint, that students when being in the process of changing one's major may frequently be more focused due to a clear goal and therefore go through the phases as postulated - thus, are not caught up in a vicious circle. When being in the process of quitting studies at all, students do not seem to follow a rational order of differentiated steps in the beginning of the decisionmaking process to the same degree as students who think about changing their major. This again emphasizes the differentiation between these two decisions.

In line with our third hypothesis, we found significant correlations of the different phases with emotional, motivational, behavioural as well as cognitive/affective variables associated with student dropout. The direction of the correlations is consistent with previous findings (e.g., Bäulke et al., 2018; Heublein et al., 2017; Krejtz \& Nezlek, 2016; Ruthig et al., 2007), since subjective well-being, academic self-concept and subjective task value correlated negatively with the phases of intentions to quit studies completely and intentions to change a major, whereas there were positive correlations of the assumed phases with anxiety, academic procrastination and learned helplessness. This finding is in line with the assumed process model. Furthermore, it implies that intentions to quit studies completely and intentions to change a major can be associated with negative emotional, motivational, behavioral and cognitive/affective aspects and thus interventions should be derived in order to support the student in the decision-making process. Additionally, descending descriptive correlations in progressing phases could be detected. The decreasing correlational strength is consistent with previous literature as it can be explained by a narrowed information search of an individual in an ongoing decision-making process (see Gollwitzer, 2012). This indicates that these 
correlates of student dropout play an important role especially in the early stages of intentions to quit studies completely and intentions to change a major.

Taken together, a process-oriented approach on dropout intentions has not been studied in detail yet, but has several advantages. First, dropout intentions can be considered in a differentiated way. Thus, individual phases are recognizable until the actual dropout decision, which enables us to understand the decision-making process of student dropout. This leads to a second advantage of the present study, as this makes it possible to identify students in their dropout process and diagnose them individually, so an individual consultation is possible. This seems to be especially important in early phases, particularly for students who leave university despite solid academic performance (Lehmann, 2007), as the first phase of the dropout process can start the whole process until the actual dropout. In previous research, intentions to quit studies completely and intentions to change a major were confused. So overall, a third strength of this study is the differentiation between intentions to quit studies completely and intentions to change a major, thereby avoiding a bias of the effects while examining student dropout (e.g., Berger et al., 2005; Cope \& Hannah, 1975; Stratton et al., 2005). Fourth, on this basis, suitable interventions depending on the phase of the dropout process can be conceived in order to prevent student dropout in early phases or help students in later phases to find a suitable alternative. Therefore, the content of interventions could and should be adapted to a specific dropout phase. Possible content includes supportive measures concerning student-system integration for reducing a non-fit perception (e.g., mentoring), counselling services for students with thoughts of quitting/changing and students who are already deliberating a dropout, information centres for students who search for targeted information, and finally a contact point for getting help concerning new alternatives in order to reduce subjective discomfort and anxiety after the decision to drop out from studies or to change a major is made. In contrast to Tinto's student departure theory that is criticized for being too broad in its treatment (e.g. Metz, 2004; Tierney, 1992), this model can thus help us 
to provide nuanced interventions. However, further studies should, based on the postulated model, examine under which conditions quitting studies completely or changing one's major is functional or dysfunctional and thereby establish profound interventions. Another aspect that we did not account for is the support of university instructors that can also be essential for successful integration (Bensimon, 2007). A next and interesting step would be to determine how instructors and student counsellors can intervene and provide help in different phases of the dropout process.

The study has some limitations that should be taken into account when interpreting our results. First, we examined students regardless of disciplines and semester. It would be interesting for future research to test our assumed model especially with first semester students as they have to manage the transition from school to university and dropout rates are particularly high at the end of the first semester (e.g., Heublein \& Wolter 2011). However, the current approach allowed us to examine a large student sample and results that are generalizable over subjects or semesters. On the other hand, a second limitation restricts the generalizability of the findings: The sample was recruited from a single German universityalthough this university is a typical public mid-size university with a typical range of degree programs and, thus, can be seen as representative for many universities in the German context. Additionally, from a theoretical point of view, the structure of the process of developing dropout intentions can be seen as relatively independent of specific institutional characteristics (although they might impact the pace with which the different phases are passed through) and as compatible to a wide range of reasons behind quitting studies or changing a major that might be more or less pronounced in different institutions (such as low performance, lack of study motivation, problems of financing studies; see Heublein, 2014). Nevertheless, future research should take multiple institutions from different countries into account in order to empirically test the generalizability of the proposed model. Here, it would be also desirable to have a longitudinal design. In this way, it could be examined if students 
go through the different phases over the course of time for confirming the presumed order of the phases and determining how long each phase lasts (in different institutions). A further limitation is that the study was based on self-reported data and not on objective data. It would be especially interesting to confirm our postulated model further by recording actual dropout or actual changes in major and integrate it into our assumed model after the phase in which the decision was made. This would consolidate the findings of Mashburn (2000) that dropout intentions predict actual student dropout. Finally, further phases after the actual dropout could be examined (for instance a post-dropout phase, see Rivière, 1999; a postselectional phase, see Betsch, 2005; an actional as well as postactional phase, see Achtziger \& Gollwitzer, 2010).

Despite these limitations, the present study contributes to a better understanding of the process of developing dropout intentions and distinguishes between intentions to quit studies completely and intentions to change a major. It is therefore a further step towards understanding the complexity of the individual student dropout process.

\section{Conclusion}

Overall, the results are in line with the assumptions of the proposed process model of developing intentions to quit studies completely and intentions to change a major. With the present findings, the conception of different phases of developing intentions to quit studies completely or intentions to change a major can theoretically be used to better understand, for example, involved regulatory processes, and practically for developing a diagnostic instrument for the early detection of student dropout in order to provide specific counselling and thereby enhance study success. 


\section{References}

Achtziger, A., \& Gollwitzer, P. M. (2010). Motivation and volition in the course of action. In J. Heckhausen \& H. Heckhausen (Eds.), Motivation and action ( ${ }^{\text {nd }}$ ed., pp. 275-299). New York, NY: Cambridge University Press.

Arendt, J. N. (2013). The effect of public financial aid on dropout from and completion of university education. Empirical Economics, 44(3), 1545-1562. https://doi.org/10.1007/s00181-012-0638-5

Bäulke, L., Eckerlein, N. \& Dresel, M. (2018). Interrelations between motivational regulation, procrastination and study dropout intentions. Unterrichtswissenschaft, 46(4), 461-479. https://doi.org/10.1007/s42010-018-0029-5

Bean, J. P., \& Metzner, B. S. (1985). A conceptual model of nontraditional undergraduate student attrition. Review of Educational Research, 55(4), 485-540. https://doi.org/10.3102/00346543055004485

Beierlein, C., Kovaleva, A., László, Z., Kemper, C. J., \& Rammstedt, B. (2014). Eine SingleItem-Skala zur Erfassung der Allgemeinen Lebenszufriedenheit [A single-item scale measuring general life satisfaction]. Köln, Germany: GESIS.

Bensimon, E. M, (2007). The underestimated significance of practitioner knowledge in the scholarship on student success. The Review of Higher Education, 30(4), 441-469. https://doi.org/10.1353/rhe.2007.0032.

Berger, J. B., \& Lyon, S. C. (2005). Past to present: A historical look at retention. In A. Seidman (Ed.), College student retention (2 ${ }^{\text {nd }}$ ed., pp. 1-29). Westport, Connecticut: Praeger Publishers.

Betsch, T. (2005). Wie beeinflussen Routinen das Entscheidungsverhalten? [How do routines influence decision making?]. Psychologische Rundschau, 56(4), 261-270. https://doi.org/10.1026/0033-3042.56.4.261 
Blüthmann, I., Lepa, S., \& Thiel, F. (2008). Studienabbruch und -wechsel in den neuen Bachelorstudiengängen [Study drop-out in the new bachelor program]. Zeitschrift für Erziehungswissenschaft, 11(3), 406-429. https://doi.org/10.1007/s11618-008-0038-y

Bong, M., \& Skaalvik, E. M. (2003). Academic self-concept and self-efficacy: How different are they really? Educational Psychology Review, 15(1), 1-40. https://doi.org/10.1023/A:1021302408382

Breitkopf, L. (1985). Zur Validität und Nützlichkeit der Hilflosigkeitsskala HiS in klinischpsychologischen und medizin-psychologischen Untersuchungen [The validity and usefulness of the helplessness scale in psychological investigations conducted in the clinical and medical fields]. Diagnostica, 31(4), 324-332. Retrieved April, 22, 2020 from https://psycnet.apa.org/record/1987-17548-001

Chemers, M. M., Hu, L. T., \& Garcia, B. F. (2001). Academic self-efficacy and first year university student performance and adjustment. Journal of Educational Psychology, 93(1), 55-64. https://doi.org/10.1037//0022-0663.93.1.55

Chen, R., \& DesJardins, S. L. (2008). Exploring the effects of financial aid on the gap in student dropout risks by income level. Research in Higher Education, 49(1), 1-18. https://doi.org/10.1007/s11162-007-9060-9

Cope, R. G., \& Hannah, W. (1975). Revolving university doors: The causes and consequences of dropping out, stopping out, and transferring. New York: John Wiley \& Sons.

De Lourdes Machado, M., Brites, R., Magalhães, A., \& Sá, M. J. (2011). Satisfaction with higher education: Critical data for student development. European Journal of Education, 46(3), 415-432. https://doi.org/10.1111/j.1465-3435.2011.01489.x

De Witte, K., \& Rogge, N. (2013). Dropout from secondary education: all's well that begins well. European Journal of Education, 48(1), 131-149. https://doi.org/10.1111/ejed.12001 DeWitz, S. J., Woolsey, M. L., \& Walsh, W. B. (2009). University student retention. Journal of University Student Development, 50(1), 19-34. https://doi.org/10.1353/csd.0.0049 
Dresel, M., \& Grassinger, R. (2013). Changes in achievement motivation among university freshmen. Journal of Education and Training Studies, 1(2), 159-173. https://doi.org/10.11114/jets.v1i2.147

Duque, L. C. (2014). A framework for analysing higher education performance: students' satisfaction, perceived learning outcomes, and dropout intentions. Total Quality Management \& Business Excellence, 25(1-2), 1-21. https://doi.org/10.1080/14783363.2013.807677

Gensch, K., \& Kliegl, C. (2012). Studienabbruch in MINT-Fächern-welche Gegenmaßnahmen können Hochschulen ergreifen? [Study dropout in STEM subjects]. Munich, Germany: IHF.

Ghassemi, M., Bernecker, K., Herrmann, M., \& Brandstätter, V. (2017). The process of disengagement from personal goals. Personality and Social Psychology Bulletin, 43(4), 524-537. https://doi.org/10.1177/0146167216689052

Gollwitzer, P. M. (1990). Action phases and mind-sets. Handbook of motivation and cognition: Foundations of social behavior, 2, 53-92. Retrieved April, 22, 2020 from https://www.socmot.unikonstanz.de/sites/default/files/90_Gollwitzer_Action_Phases_MindSets.pdf

Gollwitzer, P. (2012). Mindset theory of action phases. In: P. A. Lange Van (Eds), Theories of social psychology (pp. 526-545). Los Angeles: Sage.

Grunschel, C., Schwinger, M., Steinmayr, R., \& Fries, S. (2016). Effects of using motivational regulation strategies on students' academic procrastination, academic performance, and well-being. Learning and Individual Differences, 49, 162-170. https://doi.org/10.1016/j.lindif.2016.06.008

Heublein, U. (2014). Student drop-out from german higher education institutions. European Journal of Education, 49(4), 497-513. https://doi.org/10.1111/ejed.12097 
Heublein, U., Hutzsch, C., Isleib, S., König, R., Richter, J., Woisch, A. (2017). Ursachen des Studienabbruchs und beruflicher Verbleib von Studienabbrechern. [Causes of university dropout and job retention]. Hannover, Germany: DZHW.

Heublein, U., Spangenberg, H. \& Sommer, D. (2003). Ursachen des Studienabbruchs: Analyse 2002 [Causes of study dropout: Analysis of 2002]. Hannover, Germany: HIS $\mathrm{GmbH}$.

Heublein, U., \& Wolter, A. (2011). Studienabbruch in Deutschland: Definition, Häufigkeit, Ursachen, Maßnahmen [Drop-out from higher education in Germany]. Zeitschrift für Pädagogik, 57(2), 214-236. urn:nbn:de:0111-opus-87168

Hom, P. W., Caranikas-Walker, F., Prussia, G. E., \& Griffeth, R. W. (1992). A metaanalytical structural equations analysis of a model of employee turnover. Journal of Applied Psychology, 77(6), 890-909. https://doi.org/10.1037/0021-9010.77.6.890

Hu, L. T., \& Bentler, P. M. (1999). Cutoff criteria for fit indexes in covariance structure analysis. Structural Equation Modeling: A Multidisciplinary Journal, 6(1), 1-55. https://doi.org/10.1080/10705519909540118

Klingsieck, K. B., Grund, A., Schmid, S., \& Fries, S. (2013). Why students procrastinate: A qualitative approach. Journal of College Student Development, 54(4), 397-412. https://doi.org/10.1353/csd.2013.0060

Krejtz, I., \& Nezlek, J. B. (2016). Domain specific relationships between intellectual helplessness and academic performance. The Journal of Social Psychology, 156(6), 664-668. https://doi.org/10.1080/00224545.2016.1152219

Lehmann, W. (2007). The role of habitus in university dropout decisions. Canadian Journal of Higher Education, 37(2), 89-110.

Little, T. D., Cunningham, W. A., Shahar, G., \& Widaman, K. F. (2002). To parcel or not to parcel: Exploring the question, weighing the merits. Structural Equation Modeling, 9(2), 151-173. https://doi.org/10.1207/S15328007SEM0902_1 
Maier, S. F., \& Seligman, M. E. (1976). Learned helplessness: theory and evidence. Journal of Experimental Psychology: General, 105(1), 3-46.

Mashburn, A. J. (2000). A psychological process of university student dropout. Journal of University Student Retention, 2(3), 173-190. https://doi.org/10.2190/U2QB-52J9-GHGP6LEE

Melguizo, T., Torres, F. S., \& Jaime, H. (2011). The association between financial aid availability and the college dropout rates in Colombia. Higher Education, 62(2), 231247. https://doi.org/10.1007/s10734-010-9385-8

Metz, G. W. (2004). Challenge and changes to Tinto's persistence theory: A historical review. Journal of College Student Retention: Research, Theory \& Practice, 6(2), 191-207. https://doi.org/10.2190/M2CC-R7Y1-WY2Q-UPK5

Morrow, J., \& Ackermann, M. (2012). Intention to persist and retention of first-year students: The importance of motivation and sense of belonging. College Student Journal, 46(3), 483-491. Retrieved April, 20, 2020 from https://www.ingentac onnect.com/content/prin/csj/2012/00000046/00000003/art00003

Muthén, L. K., \& Muthén, B. O. (1998-2011). Mplus User's Guide. Sixth Edition. Los Angeles, CA: Muthén \& Muthén.

OECD (2017). Education at a Glance 2017: OECD Indicators. Paris, France: OECD Publishing. https://doi.org/10.1787/eag-2017-en

Pascarella, E. T., Smart, J. C., \& Ethington, C. A. (1986). Long-term persistence of two-year university students. Research in Higher Education, 24(1), 47-71. https://doi.org/10.1007/BF00973742

Pekrun, R., Elliot, A. J., \& Maier, M. A. (2009). Achievement goals and achievement emotions: Testing a model of their joint relations with academic performance. Journal of Educational Psychology, 101(1), 115-135. https://doi.org/10.1037/a0013383 
Pekrun, R., Goetz, T., Titz, W., \& Perry, R. P. (2002). Academic emotions in students' selfregulated learning and achievement: A program of qualitative and quantitative research. Educational Psychologist, 37(2), 91-105. https://doi.org/10.1207/S15326985EP3702_4

Pekrun, R., Goetz, T., \& Perry, R. P. (2005). Achievement Emotions Questionnaire (AEQ). User's manual. Munich, Germany: Department of Psychology, University of Munich.

Respondek, L., Seufert, T., Stupnisky, R., \& Nett, U. E. (2017). Perceived academic control and academic emotions predict undergraduate university student success. Frontiers in Psychology, 8, 1-18. https://doi.org/10.3389/fpsyg.2017.00243

Rivière, B. (1999). The psychosocial process of college dropout: The CEGEP Experience. Canadian Journal of Counselling, 33(4), 277-292. Retrieved April, 22, 2020 from https://eric.ed.gov/?id=EJ603024

Robbins, S. B., Lauver, K., Le, H., Davis, D., Langley, R., \& Carlstrom, A. (2004). Do psychosocial and study skill factors predict university outcomes? A meta-analysis. Psychological Bulletin, 130(2), 261-288. https://doi.org/10.1037/0033-2909.130.2.261

Ruthig, J. C., Haynes, T. L., Perry, R. P., \& Chipperfield, J. G. (2007). Academic optimistic bias: Implications for university student performance and well-being. Social Psychology of Education, 10(1), 115-137. https://doi.org/10.1007/s11218-006-9002-y

Sarcletti, A., \& Müller, S. (2011). Zum Stand der Studienabbruchforschung. [The state of research on dropout from higher education]. Zeitschrift für Bildungsforschung, 1(3), 235248. https://doi.org/10.1007/s35834-011-0020-2

Schöne, C.; Dickhäuser, O.; Spinath, B., \& Stiensmeier-Pelster, J. (2002). Skalen zur Erfassung des schulischen Selbstkonzepts: SESSKO. [Measurement scales for the assessment of school's self-concept]. Göttingen, Germany: Hogrefe.

Scott, G., Shah, M., Grebennikov, L., \& Singh, H. (2008). Improving Student Retention: A University of Western Sydney Case Study. Journal of Institutional Research, 14(1), 923. Retrieved April, 20, 2020, from https://eric.ed.gov/?id=EJ1055597 
Simpson, W. K., \& Pychyl, T. A. (2009). In search of the arousal procrastinator: Investigating the relation between procrastination, arousal-based personality traits and beliefs about procrastination motivations. Personality and Individual Differences, 47(8), 906-911. https://doi.org/10.1016/j.paid.2009.07.013

Solberg Nes, L., Evans, D. R., \& Segerstrom, S. C. (2009). Optimism and university retention: Mediation by motivation, performance, and adjustment. Journal of Applied Social Psychology, 39(8), 1887-1912. https://doi.org/10.1111/j.1559-1816.2009.00508.x

Steel, P. (2007). The nature of procrastination: A meta-analytic and theoretical review of quintessential self-regulatory failure. Psychological Bulletin, 133(1), 65-94. https://doi.org/10.1037/0033-2909.133.1.65

Stöber, J. \& Joormann, J. (2001). Worry, procrastination, and perfectionism: Differentiating amount of worry, pathological worry, anxiety, and depression. Cognitive Therapy and Research, 25(1), 49-60. https://doi.org/10.1023/A:1026474715384

Stratton, L. S., O’Toole, D. M., \& Wetzel, J. N. (2005). Comparing first term and first year university attrition. Virginia Economic Journal, 10, 29-44.

Tierney, W. G. (1992). An anthropological analysis of student participation in college. Journal of Higher Education, 63(6), 603-618. https://doi.org/10.1080/00221546.1992.11778391

Tinto, V. (1975). Dropout from higher education: A theoretical synthesis of recent research. Review of Educational Research, 45(1), 89-125. https://doi.org/10.3102/00346543045001089

Tuckman, B. W. (1991). The development and concurrent validity of the procrastination scale. Educational and Psychological Measurement, 51(2), 473-480. https://doi.org/10.1177/0013164491512022

Vallerand, R. J., Fortier, M. S., \& Guay, F. (1997). Self-determination and persistence in a real-life setting: toward a motivational model of high school dropout. Journal of 
Personality and Social psychology, 72(5), 1161-1176. https://doi.org/10.1037/00223514.72.5.1161

Witter, R. A., Okun, M. A., Stock, W. A., \& Haring, M. J. (1984). Education and subjective well-being: A meta-analysis. Educational Evaluation and Policy Analysis, 6(2), 165-173. https://doi.org/10.3102/01623737006002165

Wolter, S. C., Diem, A., \& Messer, D. (2014). Drop-outs from Swiss Universities: An empirical analysis of data on all students between 1975 and 2008. European Journal of Education, 49(4), 471-483. https://doi.org/10.1111/ejed.12096

Zajacova, A., Lynch, S. M., \& Espenshade, T. J. (2005). Self-Efficacy, stress, and academic success in university. Research in Higher Education, 46(6), 677-706.

https://doi.org/10.1007/s11162-004-4139-z 
Table 1

Sample Items of the Newly Developed Scales for Assessing Different Phases of Intentions to Quit Studies Completely and Intentions to Change a Major

\begin{tabular}{|c|c|c|}
\hline Phase & $\begin{array}{l}\text { Intentions to quit studies } \\
\text { completely }\end{array}$ & Intentions to change a major \\
\hline & \multicolumn{2}{|c|}{ At the moment ... } \\
\hline Non-fit perception & $\begin{array}{l}\text {... I don't feel suitable for } \\
\text { studying. }\end{array}$ & $\begin{array}{l}\text {... I don't feel suitable for my } \\
\text { degree program. }\end{array}$ \\
\hline Thoughts of quitting/changing & $\begin{array}{l}\text {... I'm considering quitting my } \\
\text { studies. }\end{array}$ & $\begin{array}{l}\text {... I'm considering switching } \\
\text { my degree program. }\end{array}$ \\
\hline Deliberation & $\begin{array}{l}\text {... I'm deliberating exactly } \\
\text { what quitting my studies }\end{array}$ & $\begin{array}{l}\text {... I'm deliberating exactly } \\
\text { what a degree program change }\end{array}$ \\
\hline Information search & $\begin{array}{l}\text { would mean for me. } \\
\text {... I inform myself precisely } \\
\text { about alternatives to studying }\end{array}$ & $\begin{array}{l}\text { would mean for me. } \\
\text {... I inform myself precisely } \\
\text { about alternative degree }\end{array}$ \\
\hline Decision made & $\begin{array}{l}\text {... I've decided to quit my } \\
\text { studies completely. }\end{array}$ & $\begin{array}{l}\text {... I've decided to change my } \\
\text { degree program. }\end{array}$ \\
\hline
\end{tabular}

Note. The presented items are an English translation from the German original scales. 
Table 2

Descriptive Statistics on a Latent Level and Internal Consistencies of Intentions to Quit Studies Completely and Intentions to Change a Major

\begin{tabular}{clccccc}
\hline & & $M$ & $S D$ & $\alpha$ & Lower CI & Upper CI \\
\hline \multirow{3}{*}{$\begin{array}{c}\text { Intentions to } \\
\text { quit studies }\end{array}$ Nompletely } & Non-fit perception & 1.87 & 0.97 & .85 & 1.83 & 1.95 \\
& Deliberation & 1.87 & 1.05 & .80 & 1.71 & 1.84 \\
& Information search & 1.58 & 0.96 & .92 & 1.51 & 1.63 \\
& Decision made & 1.21 & 0.63 & .95 & 1.16 & 1.24 \\
& & & & & & \\
\multirow{2}{*}{ Intentions to } & Non-fit perception & 2.24 & 1.13 & .86 & 2.18 & 2.23 \\
& Thoughts of changing & 2.12 & 1.22 & .88 & 2.00 & 2.14 \\
& Deliberation & 1.85 & 1.23 & .94 & 1.78 & 1.93 \\
& Information search & 1.67 & 1.18 & .95 & 1.59 & 1.73 \\
& Decision made & 1.35 & 0.88 & .93 & 1.28 & 1.39 \\
\hline
\end{tabular}

Note. $N=1,005$. 
Table 3

Descriptive Statistics and Internal Consistencies of Potential Correlates Associated with Student Dropout

\begin{tabular}{lcccc}
\hline & $M$ & $S D$ & $\alpha$ & Range \\
\hline Subjective well-being & 7.99 & 1.90 & - & $1.00-11.00$ \\
Anxiety & 2.34 & 0.99 & .85 & $1.00-5.00$ \\
Academic self-concept & 3.64 & 0.69 & .82 & $1.00-5.00$ \\
Subjective task value & 4.61 & 1.31 & .88 & $1.00-6.00$ \\
Academic procrastination & 2.77 & 1.03 & .94 & $1.00-5.00$ \\
Learned helplessness & 2.21 & 0.98 & .94 & $1.00-6.00$ \\
\hline
\end{tabular}

Note. $N=1,005$. 
Table 4.

Latent Bivariate Correlations of the Assumed Phases of Intentions to Quit Studies Completely or Intentions to Change a Major and Variables Associated with Student Dropout

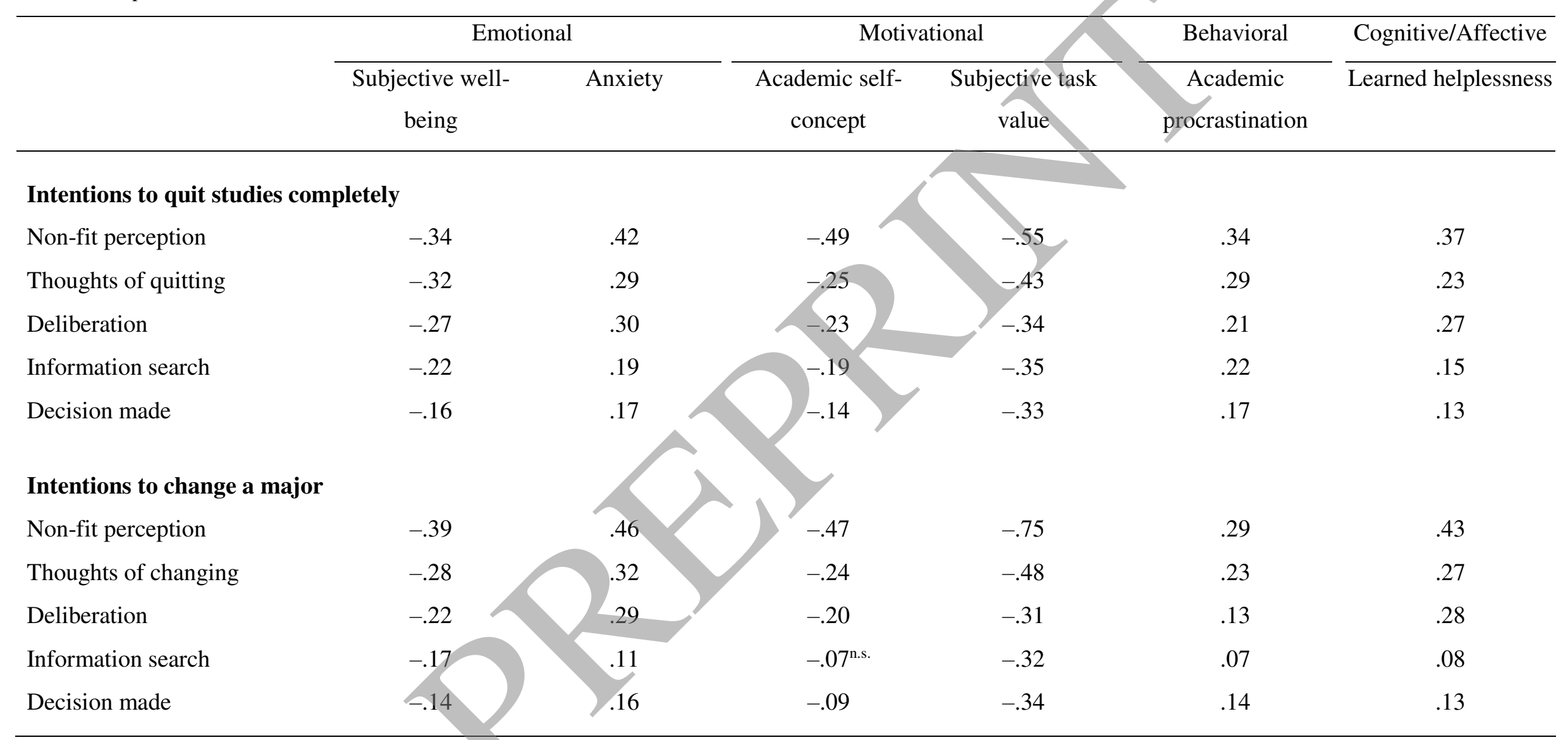

Note. All $|r|: p<.05$ except n.s. = non significant. 

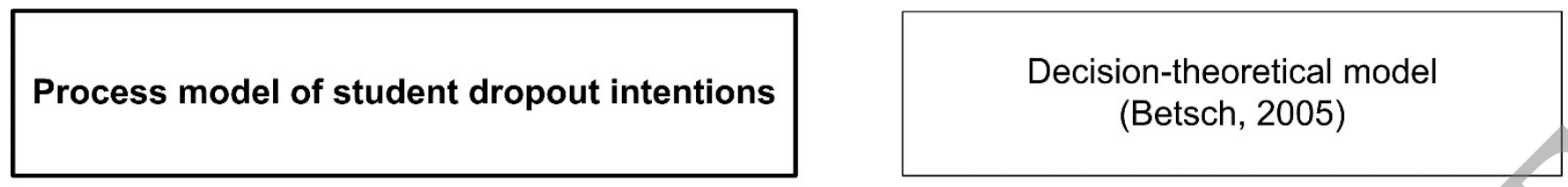

\section{Rubicon model of action phases (Achtziger \& Gollwitzer, 2010)}
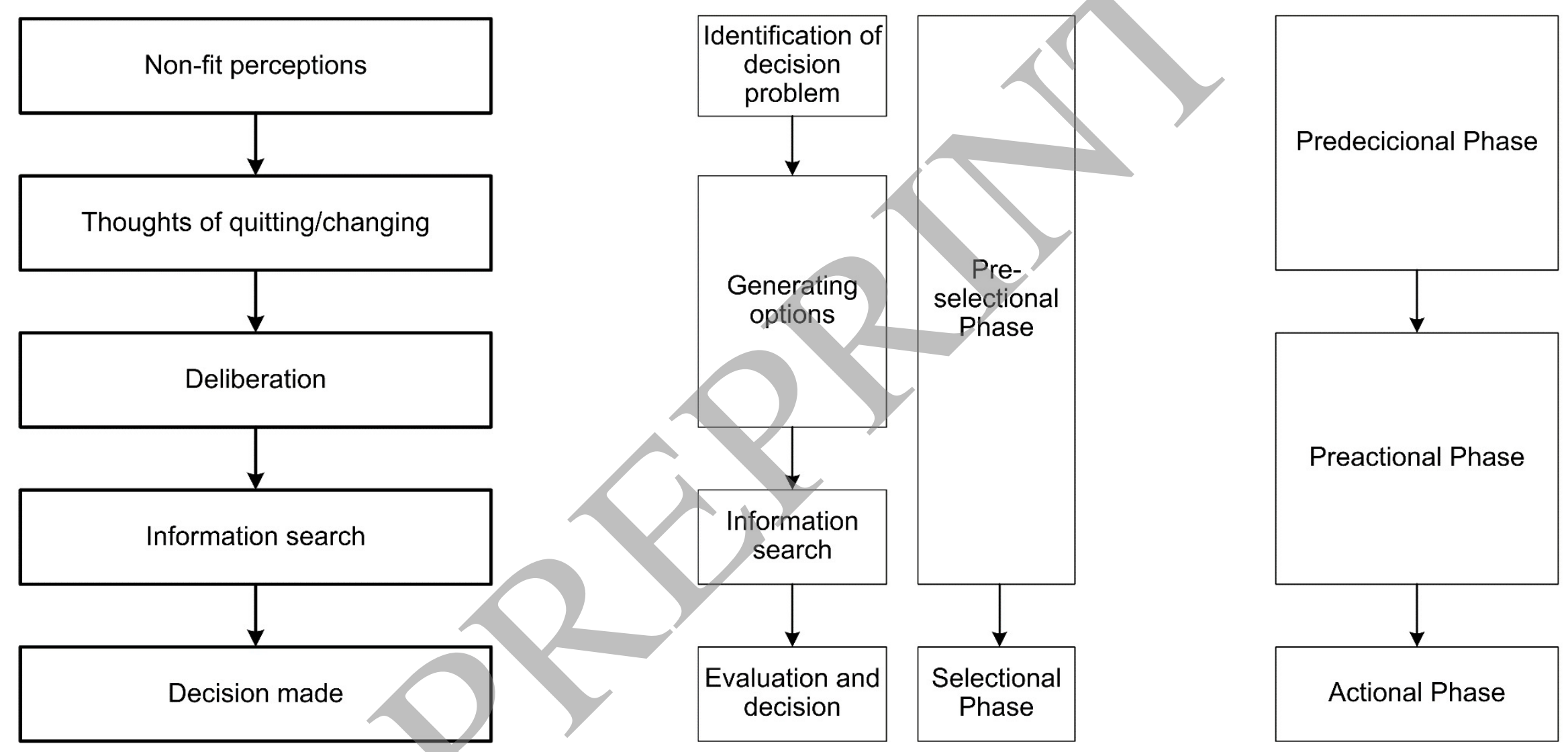

Figure 1. Theoretical model of the process of student dropout intentions based on the decision-theoretical model by Betsch (2005) and the Rubicon model of action phases (Achtziger \& Gollwitzer, 2010). 


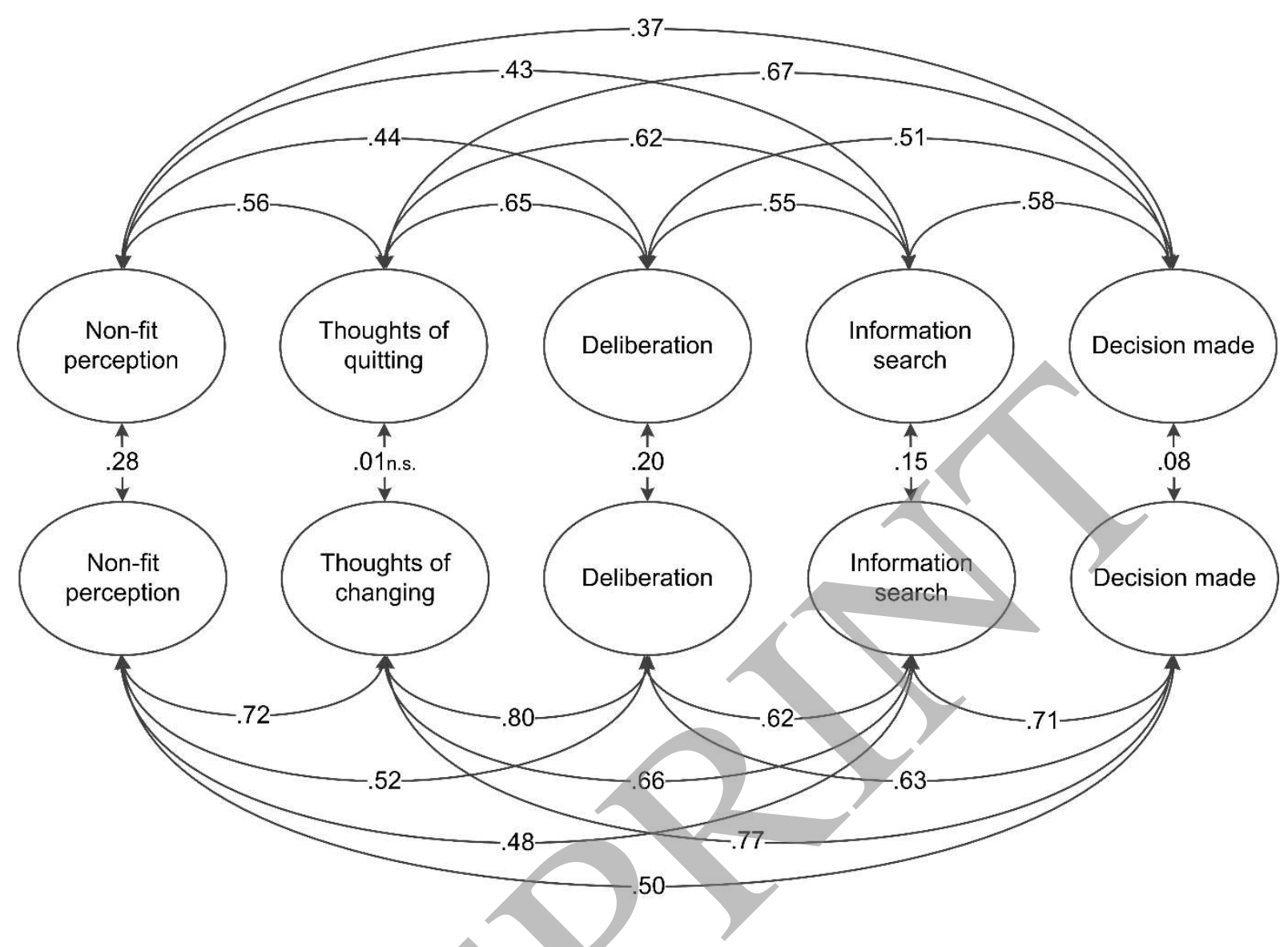

Figure 2. Results of confirmatory factor analyses of the intercorrelations of the process of intentions to quit studies completely and intentions to change a major (all latent correlations were significant at $p<.001)$. The upper row refers to the process of quitting studies completely, the bottom row refers to the process of changing a major. 


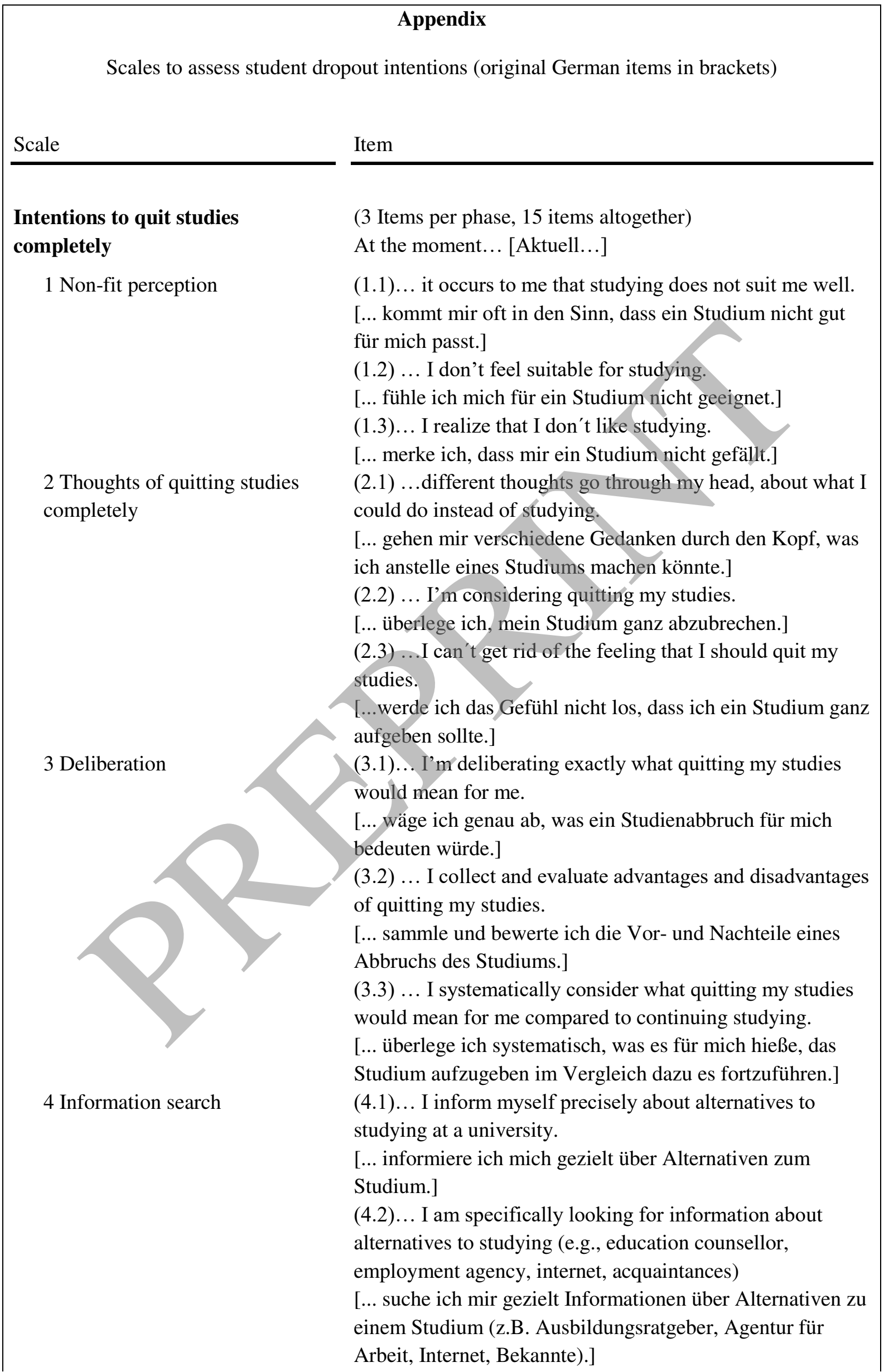


5 Decision made

\section{Intentions to change a major}

1 Non-fit perception

2 Thoughts of changing a major
(4.3) ...I thoroughly research what the requirements are for alternatives to studying (e.g., professional training).

[... recherchiere ich gründlich, welche Anforderungen in verschiedenen Alternativen zum Studium (z.B.

Berufsausbildung) gestellt werden.]

(5.1)... I've decided to quit my studies completely.

[... bin ich entschieden, das Studium ganz abzubrechen.]

(5.2) ... I'm sure that I will not continue studying.

[... bin ich mir sicher, dass ich mein Studium nicht weiter fortführe.]

(5.3) ... I'm certain that I will quit my studies.

[... steht es für mich fest, dass ich mein Studium abbrechen werde.]

(3 Items per phase, 15 items altogether)

At the moment... [Aktuell...]

(1.1) ... it occurs to me that my degree program does not suit me well.

[... kommt mir oft in den Sinn, dass mein Studiengang nicht gut für mich passt.]

(1.2) ... I don't feel suitable for my degree program.

[... fühle ich mich für meinen Studiengang nicht geeignet.]

(1.3)... I realize that I don't like my degree program.

[... merke ich, dass mir mein Studiengang nicht gefällt.]

(2.1) ...different thoughts go through my head, about what I could study instead of my degree program.

[... gehen mir verschiedene Gedanken durch den Kopf, was ich anstelle meines Studiengangs studieren könnte.]

(2.2) ... I'm considering switching my degree program. [... überlege ich, meinen Studiengang zu wechseln.]

(2.3)...I can't get rid of the feeling that I should change my degree program.

[...werde ich das Gefühl nicht los, dass ich meinen

Studiengang wechseln sollte.]

(3.1)... I'm deliberating exactly what a degree program change would mean for me.

[...wäge ich genau ab, was ein Studiengangwechsel für mich bedeuten würde.]

(3.2)... I collect and evaluate advantages and disadvantages of a degree program change.

[... sammle und bewerte ich die Vor- und Nachteile eines Studiengangwechsels.]

(3.3)... I systematically consider what switching my degree program would mean for me compared to continuing staying in my current degree program.

[... überlege ich systematisch, was es für mich hieße, in einen anderen Studiengang zu wechseln im Vergleich dazu, meinen aktuellen Studiengang weiter zu studieren.] 
4 Information search

5 Decision made
(4.1)... I inform myself precisely about alternative degree programs.

[... informiere ich mich gezielt über andere Studiengänge.]

(4.2) ... I am specifically looking for information about other degree programs (e.g., student guidance, internet, acquaintances).

[... suche ich mir gezielt Informationen über andere Studiengänge (z.B. Studienratgeber, Studienberatung, Internet, Bekannte).]

(4.3)...I thoroughly research what the requirements are for other degree programs. [... recherchiere ich gründlich, welche Anforderungen in anderen Studiengängen gestellt werden.]

(5.1)... I've decided to change my degree program.

[... bin ich entschieden, den Studiengang zu wechseln.] (5.2)... I $\mathrm{m}$ sure that I will not continue my degree program. [... bin ich mir sicher, dass ich meinen Studiengang nicht weiter fortführe.]

(5.3)... I'm certain that I will change my degree program. [... steht es für mich fest, dass ich meinen Studiengang wechseln werde.] 